\title{
Ödünç Kentsel Mekanlar: Bir Meydan Çözümlemesi, Viyana Belediye Meydanı (Wiener Rathausplatz)
}

\author{
İnci Basa \\ Orta Doğu Teknik Üniversitesi
}

Öz

Bu makale "ödünç mekan" kavramını, kentsel açık alanları 'olasıllklar ortamına' dönüştüren bir mekanizma olarak tartışmakta ve bu anlayışla Viyana Belediye Meydanı'nı (Wiener Rathausplatz) farklı pratiklere olanaklar sunan bir ödünç mekan olarak teşhis edip çözümlemeyi hedeflemektedir. Buradaki özgün katkı, bu mekanizmanın, kentlerin karmaşık yapısını anlamakta kullanılagelen 'toplumsal süreçler' ve 'mekansal biçimlenme' ikilisi arasında bir dilsel çeviri olarak betimlenmesi ve bunun söz konusu kamusal mekanın / Meydan'ın çözümlemesinde bir kuramsal çerçeve olarak kullanılması şeklinde tariflenebilir. Kamusallık kavramı, topluma ait olmak kadar devlete dair olmayı da ima eden anlam ikililiğini sıklıkla mekana, özellikle de, devlet eliyle tahsis ve tanzim edilmiş olana yansıtır. Oysa ki, kamusal mekanlar, yoğunluğu giderek artan kentlerde, mekansal çözülmeye karşı direnç yüzeyleri oluşturma potansiyeline sahiptir. Nitekim, zihinlerde, iyi bir kent imgesi ile kentlerdeki canlı kamusal mekanlar çoğunlukla iç içedir. Bu savı doğrulayan kentlerden biri olan Viyana, bunu elle tutulur kılan pek çok kamusal mekanla, meydanlarla, parklarla, ve daha önemlisi, bu mekanları etkin biçimde yaşama katan bir kentlilik kültürüyle anılır. Bu bağlamda, Viyana Belediye Meydanı da sosyal, politik, kültürel, sanatsal, sportif etkinlikler aracılığıyla dinamik bir kamusal mekan olarak kentlinin gündelik yaşam pratiklerine dahil olmakta, böylelikle kendisini fiziksel olarak çeoreleyen neo-klasik üsluptaki belediye, parlamento, üniversite ve tiyatro yapılarının kurumsal ve tektonik anıtsallğ̆ııı ötesinde yeni bir kentsel I mekansal anlama ulaşmaktadır. Viyana Belediye Meydanı'nın ürettiği bu anlam, bir ödünç mekan olarak, toplumun her kesimi için erişilebilirlik ve kentliyle kurulan güçlü kentsel bağdır.

Anahtar Kelimeler: Ödünç mekan, kentsel bă̆g, gündeliklik, mekansal pratik, Viyana Belediye Meydanı 


\title{
Borrowed Urban Spaces: Analysis of a Square, Vienna City Hall Square (Wiener Rathausplatz)
}

\author{
İnci Basa \\ Middle East Technical University
}

\begin{abstract}
This article discusses the concept of "borrowed space" as a mechanism that transforms the urban open spaces into a 'locus of possibilities', and within this understanding, it aims to analyse the Vienna City Hall Square (Wiener Rathausplatz) through its identification as a borrowed space that introduces different practices. The original contribution here can be described as this mechanism's representation as a translation between 'social processes' and 'spatial form', (the dual components which have been widely recognized in the understanding of complexity of the urban structure) and its utilization as a theoretical framework within the analysis of the Square in question. The concept of publicness frequently reflects its semantic duality (that of belonging to the society yet implying a relationality with state) upon the space, especially upon the ones organized by the state. However, in the cities with an ever-growing density, public spaces actually possess a certain potential of becoming the grounds of counter-resistance against the spatial dissociation. As a matter of fact, in one's mind, the image of a good city and lively urban public spaces are mostly intertwined. Vienna, as one of the European cities affirming this argument, is best known for its numerous public spaces, squares, parks, and moreover for its urban(ite) culture that integrates these spaces into life effectively. Within this understanding, the Vienna City Hall Square participates to the urbanite's everyday practices as a dynamic urban public space via the social, political, cultural, artistic, sportive facilities, thus, transcends the institutional and tectonic monumentality of the surrounding neo-classical buildings of City Hall, Parliament, University and Theatre by a new urban / spatial meaning. This meaning produced by the Vienna City Hall Square as a borrowed space stands for an accessibility for all social strata of the society and a strong urban bond with the citizens.
\end{abstract}

Keywords: Borrowed space, urban bond, everydayness, spatial practice, Vienna City Hall Square 
“Toplumsal ve mekansal analizi ayıran arayüzdeki karmaşık sorunlarla başa çıkabilmeye uygun bir analitik çerçeveye ihtiyacımız var. Yakın gelecekte bu iki yaklaşımı bütünleştirecek uygun bir üst-dilin geliştirileceğini sanmıyorum. Bu yüzden, kent kuramını inşa etmek için geçici çerçeveler oluşturmalıyız." (Harvey, 1973/2009, s. 47)

\section{Geçici bir Çerçeve ve Teşhis}

Bu yazı, kamusal mekan ve kentli arasındaki devimsel bağı, Viyana Belediye Meydanı'nın (Wiener Rathausplatz) farklı kentsel pratiklere olasılıklar sunması üzerinden tartışmayı amaçlamaktadır. ${ }^{1}$ Kamusallık kavramı, topluma ait olmak kadar devlete dair olmayı da ima eden anlam ikililiğini sıklıkla mekana, özellikle de, devlet eliyle tahsis ve tanzim edilmiş olana yansitır (Basa, 2016a). Bu ikililikte devlete dair olma vurgusunun baskınlığı, kentlilik kültürünün tam yerleşmediği veya özümsenmediği toplumlarda, neredeyse bir refleks olarak, kamusal mekan kentlinin mekansal pratiğinin dışında bir yerde konumlandırır. Bu kültürün kendiliğinden yerleşmesi ve özümsenmesi olanaklı değildir; istikrarlı bir yönetimsel çabanın ve kentli isteğinin olması gereklidir. Burada Viyana Belediye Meydanı'nın çözümlemesinden elde edilmek istenen, kendini toplumsal süreç(ler)in sosyal, politik, kültürel, sanatsal, sportif... dizgelerinden sakınmayan bu kamusal mekanın nasıl dinamik bir kentsel gündelikliğe sahip olduğunun teşhisidir (Resim 1). Bu bağlamda açıklığa kavuşması gereken önemli bir nokta, bu çözümlemede toplumsal veya mekansal normlar, birbirini dışlayan kavramsallaştırma seçenekleri olarak veya basit bir nedensellik ilişkisi içinde değil, birbirini tamamlayıcı unsurlar ve etkileşen sistemler olarak ele alınacaktır (Harvey, 1973/2009, s. 48).

Viyana Belediye Meydanı çok katılımlı etkinliklere mekânsal olanak sunma potansiyeline sahip olan ve merkezi bir konumda yer alan önemli bir kentsel alan. Ancak bu nitelikleri barındırmak, otomatik olarak kentlinin mekânsal pratiklerine etkin şekilde dahil olmak anlamına gelmemektedir. Kentlerde benzer niteliklere sahip pek çok alan kentlinin kentsel / mekânsal pratiklerinde kendine yer bulamamaktadır. Bu niteliklerin kente değer katacak bir unsura dönüşmesi için sürdürülebilir bir siyasal

\footnotetext{
${ }^{1}$ Kentlerin farklı hallerine tanıklık etmek ve bu haller üzerine 'söz söylemek', o kentlerde belli yaşam dilimlerini geçirmeyi gerektirir. Viyana' da bulunduğum 2008-2014 yılları arasına yayılan dönem, bana, kenti ve mekânsal pratikleri farklı açılımlarda gözlemleme ve belgeleme, dolayısıyla da 'söz söyleme' olanağını verdi.
} 
irade ve toplumsal talep bulunmalıdır. Viyanalılar'ın kentsel pratiklerinde hatırı sayılır bir yere sahip olan Belediye Meydanı bu statüye nasıl kavuşmuştur diye bakıldığında, bir "ödünç ver(il)me" mekanizması öne çıkmaktadır. Yani tek bir mekan ("ödünç alınan"), farklı işlevler için farklı kurum veya organizasyonlarca kullanılmaktadır (Smith, 2014). İkinci Dünya savaşı yıllarından itibaren kesintisiz olarak sosyal demokrat görüşün hakim olduğu Viyana yerel yönetimi ${ }^{2}$, belli zaman aralıklarıyla alanı "ödünç verdiği" bir mekanizmayı benimsemiştir. Kentliyi ve modern toplum dokusunu odak alan bu yönetimsel yaklaşım, Viyana Belediye Meydanı'nın, (tarihsel bir veri olarak) hali hazırda var olan devlet odaklı mekânsal hiyerarşini aşarak yeniden biçimlenmesi yönünde de güçlü bir niyeti ifade etmektedir (Haeupl, 2009).

Bu yazının hedeflediği katkı, sözkonusu mekanizmayı 'toplumsal süreçler' ve 'mekan biçimlenmesi' ikilisi arasında bir dilsel çeviri olarak betimleme denemesidir. David Harvey (1973/2009), bu ikilinin birlikte ele alınabilecek ortak bir dil olduğu varsayımının analitik bir netice getirmeyeceği saptamasını yapar; aynı şekilde, birinin diğerinin nedenselliği olması (yani, mekan biçimlenmesini toplumsal sürecin çıtısı olarak görme veya toplumsal süreci mekan biçimlenmesinin çıktısı olarak görme) yaklaşımının da saf soyutlamalar olduğunu ileri sürer. Ona göre kentin karmaşık yapısını anlamak için sıklıkla başvurulan 'toplumsal süreçler' ile 'mekan biçimlenmesi', birbirleriyle farklı şekillerde etkileşim içinde olan değişkenler olarak görülebilir. Dolayısıyla 'toplumsal süreçler' dili ile üretilen kavramsallaştırmayı 'mekan biçimlenmesi' diline çevirerek çözümleme yapmak ve sonuçlar üretmek mümkün olabilir. Ancak Harvey (1973/2009, s. 49) burada 'sorun' olarak nitelediği yöntemsel bir uyarıda bulunmaktadır: bu sorun, 'mekansal biçim / toplumsal süreç çevirisinin oturmuş belirli kuralları olmamasıdır'.

\footnotetext{
${ }^{2}$ Federal eyaletlerden oluşan bir sistemle yönetilen Avusturya'da ikisi (Viyana ve Salzburg) şehir eyaleti olan 9 eyalet bulunmaktadır. Anakent Belediye Başkanı, Viyana'nın şehir eyaleti konumu nedeniyle aynı zamanda hükümet eden eyelet başbakanıdır. İkinci Dünya Savaşı'ndan sonra onyıllar boyu sosyal demokratların yönetimde olduğu Anakent Belediyesi (-sadece son iki dönem Yeşiller ile koalisyonla) sosyal demokratik siyasal görüş çerçevesinde, insanı/kentliyi ve onun yaşam kalitesini yükseltmeyi öne çıkaran işlevsel bir altyapının önemini vurgulamaktadır. 1994 yılından itibaren Viyana'nın belediye başkanlığını yürüten Michael Haeupl, sosyal demokrasi perspektifinden, kentin altyapısının çağdaş anlayışla inşa edilmesinin temel taşı olarak kentliyi işaret eder. Bu altyapı hem uluslararası rekabette ekonomik olarak ayakta durabilmenin hem de 'insan' merkezli modern bir kent yaşamının anahtar faktördür (Haeupl, 2009).
} 
Bu görüşten yola çıkarak denilebilir ki, oturmuş genel bir kural olmasa da, yazının başlığının da işaret ettiği üzere, "ödünç mekan" kavramı yöntemsel olarak irdelenmeye değer bir altlık sunmaktadır. Lefebvre (1974/2014, s. 207)'in aktarımiyla toplumsal / kamusal mekan, 'her zaman ve eş zamanlı olarak', hem 'edimsel (verili)' hem 'potansiyel (olasılıklar ortamı)' değil midir? İşte "ödünç mekan" kavramı, kamusal mekanı bir 'olasılıklar ortamına' dönüştürme mekanizması olarak, bu yazının amaçladığ çözümlemeyi mümkün kılan bir kuramsal çerçeve tesis etmektedir.

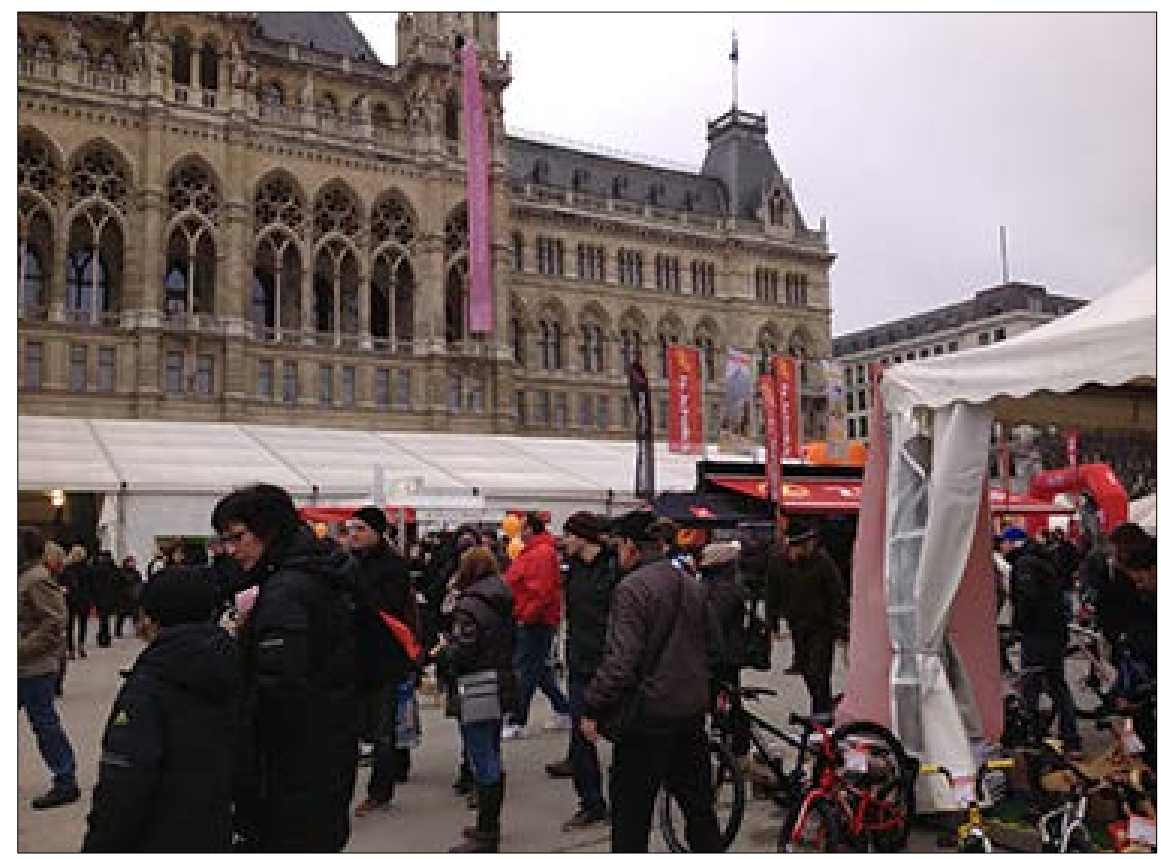

Resim 1. 'Olasılıklar ortamı' olarak Viyana Belediye Meydanı (Foto:, İnci Basa)

\section{Belleğini Sıkı Korumaya Almış bir Kent: Viyana}

Kamusal mekanlar, giderek yoğunlaşan kentlerde, mekansal çözülmeye ve belleksizleşmeye karşı direnç yüzeyleri olarak nitelendirilebilecek bir dinamiği temsil etmektedir. Çoğu zihinlerde, iyi bir kent imgesi ile canlı kentsel mekanlar iç içedir. Bu savı doğrulayan kentlerden biri şüphesiz orta Avrupa kenti Viyana'dır. Kent, bu savı elle tutulur kılan pek çok kamusal mekana, meydanlara, parklara ve bu mekanları etkin biçimde yaşama katan kent(lilik) kültürüne sahiptir. Viyana'nın kentsel dokusunu mimarlık kültürü bağlamında ayrıcalıklı kılan, kentin tarihselci / yeniden canlandırmacı 
yapılarına ve çevre düzenlemelerine eklemlenmiş erken Modern mimarlık dilidir. Bu dil, ağırlıklı olarak, 19. yüzyıl sonlarında ve 20. yüzyıl başlarında mimarlık kuram ve pratiğine yenilikçi bir soluk getiren Modern hareketin öncülerinden Otto Wagner (1841-1918) ve Adolf Loos (1870-1933) tarafından şekillenmiştir. Böylesine güçlü bir mimari temsilin kentin algısında belirleyici güzergah olması olağan bir durum. Ancak, bu yazının niyet ettiği üzere, kente, kentin belleğine ve kamusal mekanlarına, seçkin mimari çevre algisı perspektifinden değil de kentlinin gündelik yaşamı olgusundan yaklaşıldığında, bedensel, sınıfsal, zamansal, mekânsal pek çok kesişmeyi içeren farklı bir kavrayışa ulaşılır (Basa, 2016b). Kentsel mekan bir 'olasılıklar ortamı' olarak, fiziksel biçimlenmesinin ötesine geçip, ona temas eden unsurlarla birlikte yeniden üretilir; mekânsal pratiklerin eşliğinde derinleşir.

Kentleşme ve mimarlık tarihinin izlerini detaylı bir şekilde sürmeye olanak veren başkent Viyana'nın, belleğini sıkı korumaya aldığı aşikardır. Ancak burada ilginç olan bir nokta vardır. Bunu yaparken, kamusal mekanlarını "sakınarak" değil, onları modern gündelik yaşamın sıradanlığını kıran pratiklere açarak canlı tutmakta ve bu mekanların tekrar tekrar keşfine el vermektedir. ${ }^{3}$ Bu bağlamda irdelenen Viyana Belediye Meydanı, dinamik bir "ödünç mekân" olarak, farklı içeriklerle kentsel ilhamlar sunmaktadır. Meydan'ın "ödünç alınması" yoluyla gerçekleşen pek çok farklı bağlamdaki etkinlik birer festival olarak anılmakta (film festivali, bisiklet festivali, güvenlik festivali...), dolayısıyla Meydan kenti 'festivalleştiren' bir araç rolüne sahip olmaktadır (Hofer, 2008). Yılın hemen her döneminde konser, film gösterimi, spor gösterileri ve fuar gibi değişik işlevlere uygun hale getirilen ve sabit bir kent siluetine dönüşmesine izin verilmeyen bu kamusal açık alan, kentliyle arasındaki sosyal bağı, çözülmeye mahal bırakmaksızın güçlü tutmaktadır.

\section{Mekansal Pratik: Kentin Kentliyle Buluşması}

Kentlerin karmaşık yapısına bağlı olarak, farklı disiplinler kentsel mekanı kendi bakış açılarını önceleyerek açıklamakta ve kavramsallaştırmaktadır.

\footnotetext{
${ }^{3}$ Kentsel kültürü zenginleştirmek bağlamında Belediye Meydanı kadar etkin rolleri olmasa da, kentsel hafızanın önemli temsilcilerinden olan ikinci bölgedeki (Leopold Stadt) Wienerprate (1560 yılında imparatorun av alanı, bugünkü Viyana'nın ise eğlence parkı), dördüncü bölgede (Wieden) 1737 yılında inşa edilen Karlsplatz Kilise Meydanı ve birinci bölgede (Innen Stadt) tarihi 12. Yüzyıla uzanan Schottenkirche Freyung Meydanı, çeşitli sosyal, kültürel ve rekreasyonel etkinliklerle öne çıkan kamusal mekânlardır.
} 
Mimarlık disiplini için mekanın fiziksel nitelikleri onun doğasının önemli bir bileşenidir ve kentli pratiklerine şekil verir. Ancak kentli pratiklerinin de mekanın kavramsallaştırma araçlarından olduğu yadsınamaz. Bir kentin kimliğini oluşturan en önemli unsur kentlinin mekansal pratikleridir. Başta, barınma ve çalışma mekanları ve bunları birbirine bağlayan ulaşım ağı olmak üzere, her kentli, üretim, yönetim, eğitim, sağlık ve serbest zaman aktivitelerini barındıran mekanlar arasında bir gündelik örüntü kurar. Bu örüntüyü -zaman zaman kesintili de olsa- sürekli kılan, belli sıkliktaki tekrarlardır.

Mekansal pratikler her kentli için ideal bir kurguya işaret etmese de, kentliyi kente eğreti olmayan duygularla bağlayan önemli bir öğedir. Bazı kent alanları sundukları aktivitelerle kentliyi çeker ve bu örüntü içinde kendine yer açar. Bu alanlar fiziksel nitelikleriyle öne çıkan kentsel nesneler olmak yerine, dolaylı veya doğrudan kentsel müştereklikler üreten süreçler niteliğindedir. Bu yazıya konu olan Viyana Belediye Meydanı da bir “ödünç kentsel mekan" olarak dönemsel ve renkli bir programla aslen kentliye ait olduğunun altını çizer. Burada dikkat çekici bir unsur, "mutena" kültürel aktivitelerini ön plana çıkarmama, dolayısıyla belli bir toplumsal grup yerine, onu talep eden her kent sakinine ve gezginine açık olma vurgusudur. 19. Yüzyıl sonlarında meydanın mimari anıtsallığının inşa edilmesi gibi, burada bir müşterek gündeliklik metalaşmadan inşa edilmektedir.

\section{Anıtsallık, Gündeliklik ve Viyana Belediye Meydanı}

Yapımı 1872-1883 yılları arasında tamamlanan Viyana Belediye Binası, Friedrich von Schmidt (1825-1891) tarafından, döneminin gözde mimari akımı olan neo-gotik üslupta tasarlanmıştır. Yirmiüç bölgeden oluşan Viyana'da Innere Stadt oarak adlandırılan Birinci Bölge'deki (1. Gemeindebezirk) yapı $152 \mathrm{~m}$. uzunluğunda ve $127 \mathrm{~m}$. genişliğindedir. Yıkılan ortaçağ kent duvarlarının yerine yapılan ve dairesel formda kentin merkezini çevreleyen Ring Caddesi (Ring Strasse) boyunca uzanan yapı, neo-gotik üslubun geleneksel mimari niteliklerini sergilemektedir. Belediye Binası, yapımı 1858 yılında biten ve kentin neredeyse tüm sembolik, tektonik ve işlevsel önemdeki yapılı çevresinin cephe verdiği Ring Caddesi'nde, önündeki meydana ve yeşil alanına yer açacak şekilde içeri çekilmiş konumuyla kent siluetini tamamlayıcı bir rol üstlenmektedir. Doğal taş kaplamalı, sivri kemerlerle bezenmiş simetrik cephenin ortasında 98 m. yüksekliğinde bir ana kule ve yanlarda ikişer sivri kule yer almaktadır. 19. 
Yüzyıl Viyana'sının önde gelen mimarlarından olup, Viyana Güzel Sanatlar Akademisi'nde ders veren Friedrich von Schmidt, çoğu kilise yapıları olmak üzere bu Ortaçağ esintili üslubu yansıtan eserler yaratmış ve 'Viyana Gotikcisi' (Sisa, 2002) olarak ünlenmiştir (Resim 2).

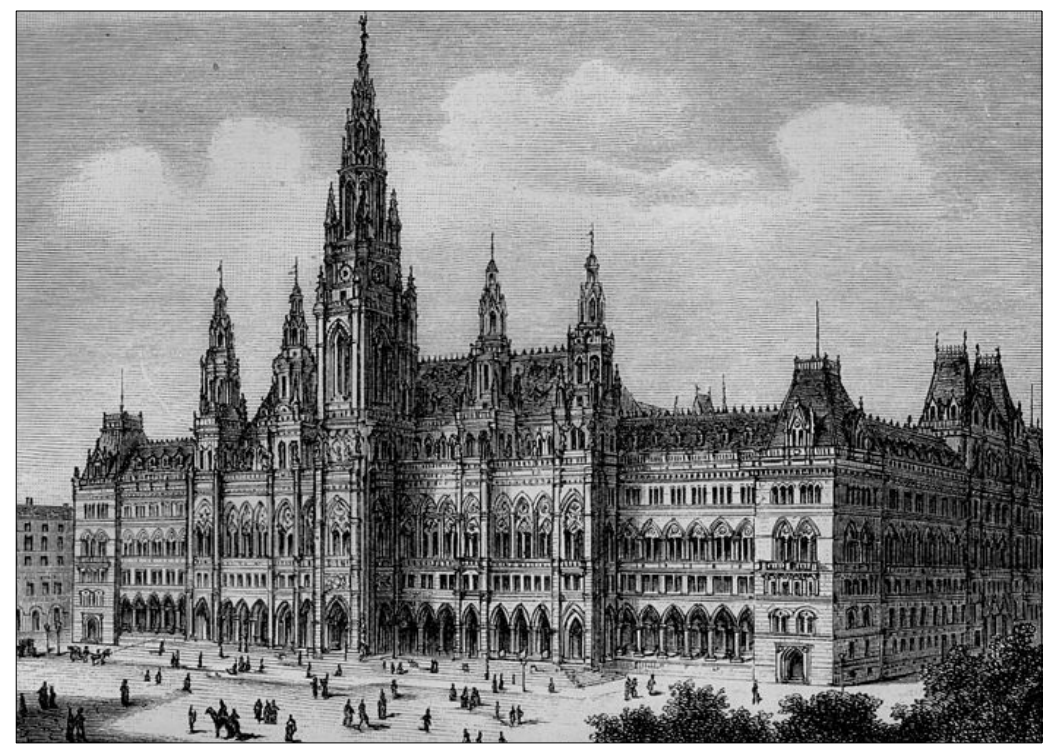

Resim 2. Belediye Binası'nın Ring Caddesi yönünden 1885 tarihli gravürü https://commons.wikimedia.org/wiki/File:Wiener_Rathaus_Brockhaus_13_Aufl.jpg?uselang=en-gb, adresinden19 Mart 2017 tarihinde erişildi.

Mimari dil, ölçek, konum ve çevre düzenleme nitelikleri itibariyle bina yerel yönetimin kurumsal kimliğini tarihselci bir anıtsallıkla vurgulamaktadır. Belediye yapısı, hemen önünde yer alan ve Viyana Belediye Meydanı olarak adlandırılan kentsel açık alanın doğal olarak en tarifleyici fiziksel verisini oluşturur. Ancak bu alanın kimliğini etkileyen ve tektonik olarak neo-gotik Belediye yapısından daha az anıtsallık iddiası taşımayan komşu(luk)lardan da söz etmek gerekir.

Belediye Meydanı'nı kısa kenarlarından, ağaçlıklı alanların komşuluğunda tarifleyen iki neo-klasik yapı, her ikisi de Ring Caddesine cömertçe açılan Parlamento ve Üniversite binalarıdır. Theophil von Hansen'in Parlamento binası (1871-1883) Meydan'ın güneyinde (Resim 3), Heinrich von Ferstel'in Viyana Üniversitesi (1874-1883) ana binası ise Meydan'ın kuzeyinde yer alır (Resim 4). Yoğun bir ağaç dokusuna sahip Rudolf Siebeck'in tasarladığı Belediye Parkı (Rathauspark) (1873) ise meydanla bu iki yapı 
ve de Ring Caddesi arasındadır. Parkı ikiye bölen geniş aks, Meydan ile Ring Caddesi'nin karşısındaki Gottfried Semper ve Karl von Hasenauer tasarımı Tiyatro Binasını (Burgtheater) (1888) bağlamaktadır (Resim 5).

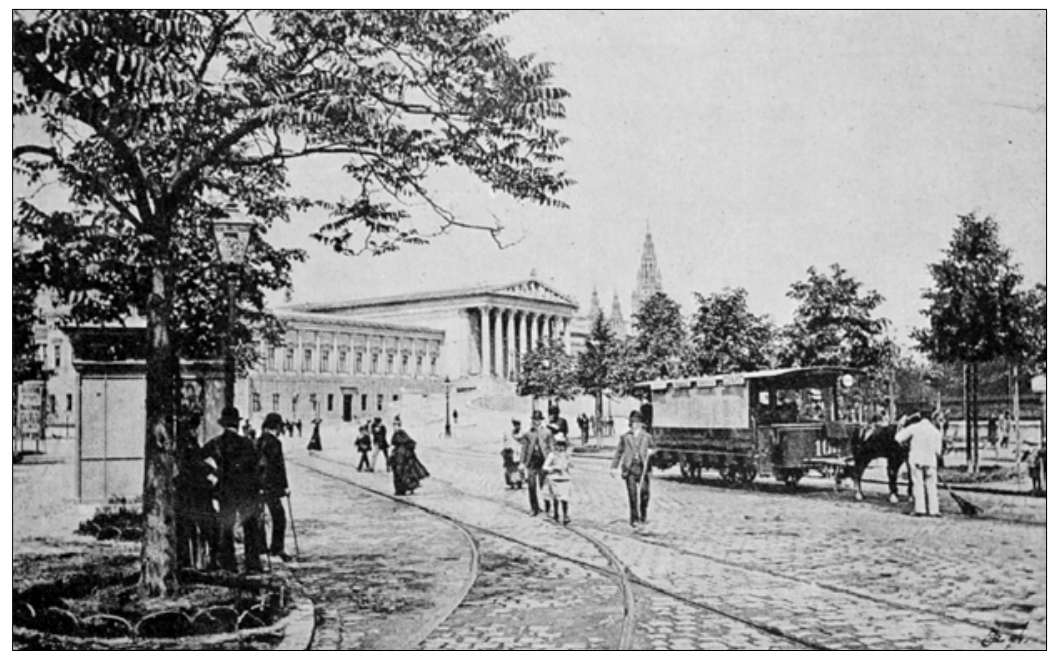

Resim 3. 1890 yılında Parlamento Binası ve Ring Caddesi https://commons.wikimedia.org/wiki/File:Wiener_Ringstra\%C3\%9Fe_mit_Parlament-Victor_Angerer-1890.jpg adresinden 19 Mart 2017 tarihinde erişildi.

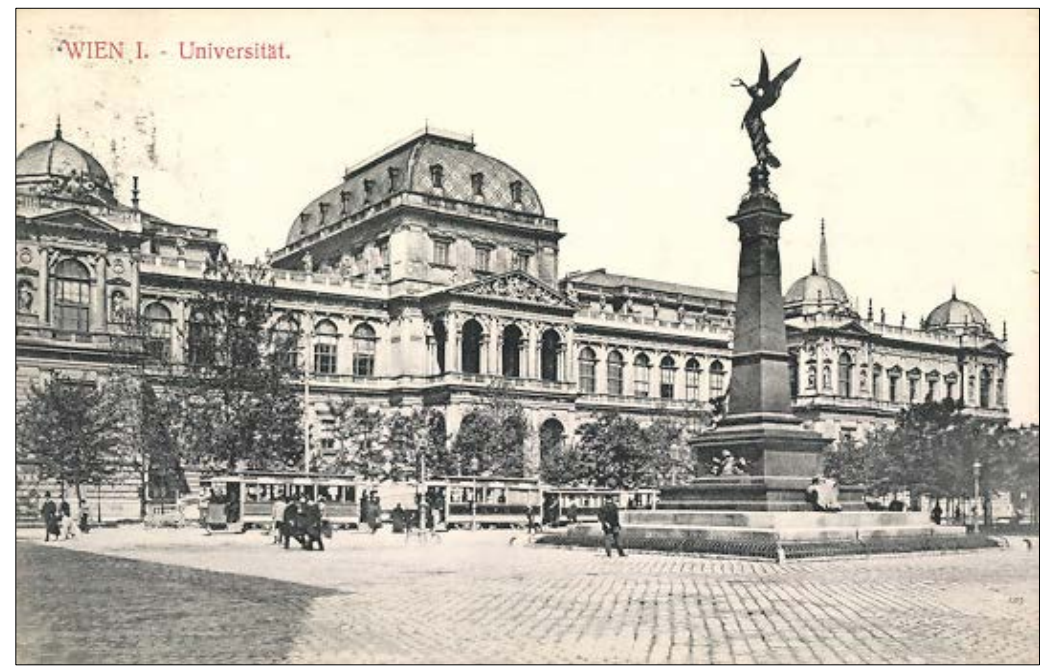

Resim 4 Viyana Üniversitesi Binası https://commons.wikimedia.org/wiki/File:Historisches_Ansichtskartenmotiv_der_Wiener_Ringstra\%C3\%9Fe_14.jpg?uselang=en-gb, adresinden 19 Mart 2017 tarihinde erişildi. 


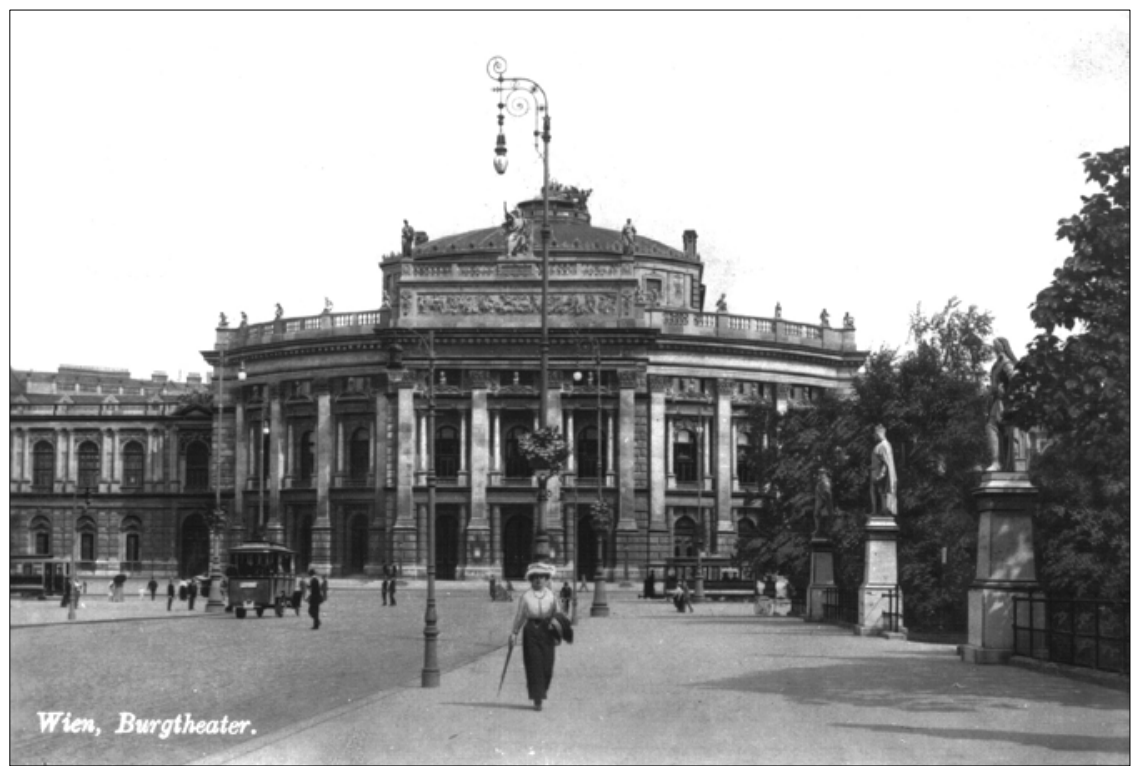

Resim 5 'İnşasından kısa bir süre sonra Tiyatro Binası', https://commons.wikimedia.org/wiki/File:Wiener_Burgtheater_alt.jpg, adresinden 19 Mart 2017 tarihinde erişildi.

$\mathrm{Bu}$ yapılardan beslenen kalıcı bir anıtsallığa sırtını yaslayan ve Ring Caddesi ile yapı arasında konumlanan Belediye Meydanı, bugün benimsenen yerel siyasetin getirisi olarak, modern gündelik yaşamın mekânsal temsili gibidir. Bu siyaset bir yandan kentin ekonomisine katkıyı gözetiyor olsa da ${ }^{4}$ (Igler, 2013), denilebilir ki, yerli ve yabancı ziyaretçi akınının hiç kesilmediği bir dünya kenti için bu bir öncelik değildir. Belediye, parlemento ve üniversite yapılarının oluşturduğu ağır mimari dilli kurumsal dokunun içinde, Belediye Meydanı'nın herkesçe erişilebilinir gündeliklik temsili incelemeye değer bir tezat sunmaktadır. Meydan, kurumsal olanla kentli arasındaki soyut mesafeyi yok etmekte ve kentliyle güçlü bir sosyal bağ kurmaktadır. Bu bağı kurabilmesinin ve kentsel kültürün etkin bir bileşeni olarak sürdürülebilir kılmasının altında yatan, Meydan'ın kendisini kültürel, sanatsal, toplumsal ve sportif aktivitelere sınırsızca açmış olmasıdır. Viyana Belediye Meydanı, durağan bir kentsel nesne olmak yerine,

\footnotetext{
4 Örneğin, Viyana Belediye Meydanı'nda gerçekleşen Noel Pazarı'nın (Wiener Christkindlmarkt) 3.5 milyon civarında ziyaretçisi ve 60 milyon Avro'luk bir cirosu bulunmakta, bu etkinlik için yaklaşık 30.000 kişi istihdam edilektedir (Igler, 2013).
} 
bir "ödünç mekan" olarak, kentin farklı kesimlerinin mekansal pratiklerine dahil olup, gündelik yaşamlarına sızmaktadır (Resim 6).
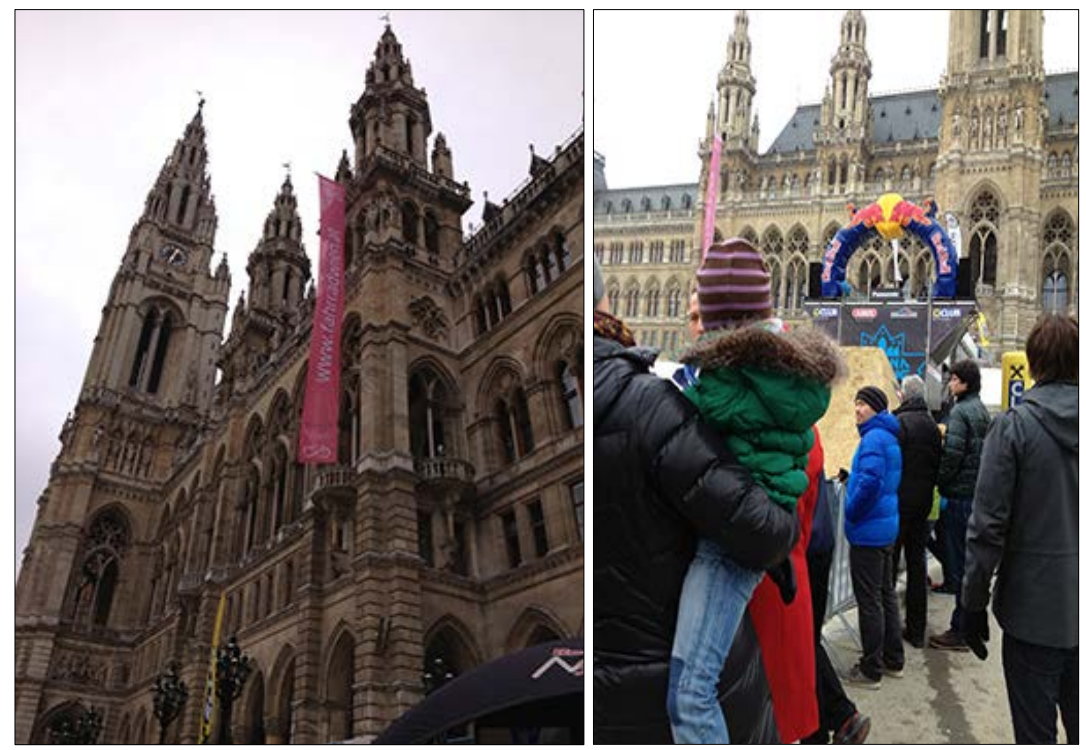

Resim 6 Viyana Belediye Binası ve Belediye Meydanı (Fotoğraf, yazarın arşivi)

\section{Olasılıklar Ortamı Olarak Viyana Belediye Meydanı}

Asi Şehirler eserinin 'Kentsel Müşterek Alanların Yaratılması' bölümünde Harvey (2012/2013, s.117)'in altını çizdiği üzere, 'kent her türden ve sınıftan insanın, her ne kadar gönülsüzce ve agonistik bir biçimde de olsa, yanyana gelerek durmadan değişen, gelip geçici, ama yine de müşterek bir yaşantıyı ürettiği mekandır'. Bu bakış açısı ile kentsel kültüre atfedilecek en önemli değer, ayrıştırıcı mevzilenmeler yerine anonim ve eşitlikçi bir tutumu mümkün kılmasıdır.

Kimliğini, yer'e sabitlenmiş bir programdan değil de, "ödünç verilebilme" olanaklarından alan kentsel mekanlar kentsel kültürü bu anlamda besler ve çok yönlü nitelikte üretir. Bu ortamda, otoriter / kalıcı / anıtsal mimari temsil de, varlığını, kentsel kültürün akışkan ve dışlamayan gündelikliğinde yeniden tanımlamak zorunda kalır. Bir bakıma mimari anıtsallıkla gündelik değişkenler çakışır. Bu çakışma gözlemlendiğinde şu savlanabilir ki, bu ikisi arasındaki güç ilişkisi el değiştirmiştir. Ele alınan Viyana Belediye Meydanı örneğinde bu çakışmadan çıkan ilginç sonuçlardan biri farklı kentsel unsurların birbirine uyum sağlama becerisidir. 
Başkent Viyana ilk bakışta bütünlüklü bir ön resim sunmakla birlikte, her göç alan büyük kent gibi heterojen bir toplumsal yapıya sahiptir (Migration und Integration, 2016). ${ }^{5}$ Bir Asi Şehir olarak nitelenemese de yaklaşık yüzde otuzunu yabancı kökenli vatandaşların oluşturduğu 1.840.226 nüfuslu bu kentte ortak, erişilebilir ve sürdürülebilir bir kentsel kültür oluşturmak için sağlam gerekçeler bulunmaktadır. Kamusal açık alanlar bu ortak kültürü tesis etmek, etnik ve sosyal farklılıklara sahip grupları / bireyleri buluşturmak ve adil bir kentsel paylaşım sağlamak için anlamlı zeminlerdir. Kültürel ve sanatsal organizasyonlara olduğu kadar bisiklet festivali gibi sıradışı etkinliklere de sıklıkla evsahipliği yapan Viyana Belediye Meydanı, kentin bu bağlamda öne çıkan kamusal mekanıdır (Resim 7).

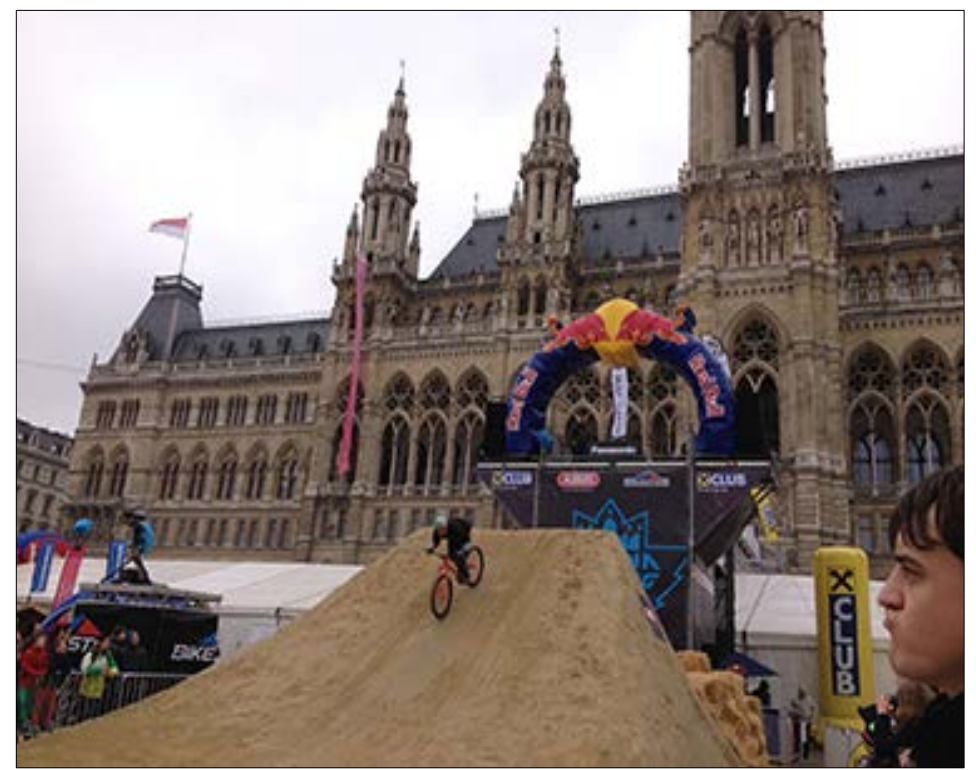

Resim 7 Etkinlik için Meydan'da oluşturulan ortam (Foto: İnci Basa)

\footnotetext{
${ }^{5}$ Migration und Integration / Zahlen, Daten, Indikatoren, BMEIA Bundesministerium für Europa, Integration und Ausseres, Federal Dışişleri Bakanlığı yayına göre, 2016 yılında 8.700.000 nüfusa sahip Avusturya'da, 1.813 .000 göçmen kökenli nüfus yaşamaktadır. Bu \%21,4'lük oran 1.840.226 nüfuslu Viyana'da \%38.3'e çıkmaktadır; yani başkent ülke geneline göre neredeyse iki kat daha fazla göçmen kökenli nüfusa sahiptir. Kent 704.900 göçmen kökenli barındırmaktadır; bunların 500.000'i yabancı bir ülkenin vatandaşlığına sahiptir. Bu sayının genel Viyana nüfusu içindeki oranı ise \%27.4'dür. Bkz., Viyana Belediyesi resmi internet sitesi http://www.wien.gv.at/menschen/integration/grundlagen/daten.html (13 Mart 2017 tarihinde erişilmiştir.)
} 
Son otuz yıldır daha çok kültür aktiviteleriyle öne çıan Meydan, tarihinde önemli siyasal etkinliklere sahne olmuştur. Belediye binasının tamamlandığ1 1883 yılı itibariyle Viyana Belediye Meydanı'nın ilk önemli ev sahipliği, 17 Eylül 1911 tarihinde yaklaşık 100.000 kişinin katıldığı büyük bir siyasal protestodur. Sosyal Demokratlar'ın çağrısıyla öncelikli olarak o dönemde yaşanan hayat pahallılığına karşı düzenlenen bu kalabalık gösteride atlı polisler ve askerlerin göstericilere müdahelesi sonucu ölenler ve yaralananlar olmuştur. Meydan, Birinci Dünya Savaşı'nı izleyen yıllarda, başta 1921 yılından itibaren düzenlenen 1 Mayıs yürüyüşleri ve gösterileri olmak üzere, çeşitli siyasal etkinlikler için kullanılmıştır. Bu tarihe kadar ilçelerde düzenlenmekte olan 1 Mayıs yürüyüşü, Ring Caddesi'ne alınmış ve yürüyüş Belediye Meydanı'nda gerçekleştirilen mitingle sonlandırılmaya başlanmıştır. Meydan hem sosyal demokratlar hem de onların rakipleri tarafından toplu görüşlerin aktarıldığı bir kamusal zemin olmuştur. Aynı zeminde sosyal demokrat Belediye yönetimince getirilen lüks tüketim vergisinin protestosu da (1920), anti-semitist (Yahudi-karşıtı) gösteriler de (1923) yer almıştır.

1933 'te Nasyonel Sosyalist yönetimce getirilen yasaklamalar, İkinci Dünya Savaşı sonrasında geçerliliğini yitirmiş ve 1946 yılı itibariyle Belediye Meydanı yine Mayıs gösterilerinin gerçekleştiği alan olmuştur. Meydan'ın geçmişinde, akıllarda kalan önemli bir tarih de 16 Eylül 1945'dir. Bu tarihte Meydan'da üç büyük siyasal partinin gençlik kollarının ortaklaşa katılımıyla Avusturya Gençlik Günü gerçekleştirilmiştir. Giderek sayıca azalan bu etkinlikler, buna karşın artan araç trafiği, 1950 yılında, kentin bir dönem en önemli kamusal mekanı olan Viyana Belediye Meydanı'nın motorlu araçların park alanına dönüşmesi kararını beraberinde getirmiştir. Etkinlik sayısının azalması, örneğin, 1950 yılı içinde 1 Mayıs gösterisi haricinde Meydan'da sadece dört gösterinin gerçekleşmiş olması mekanın başkentin kentsel kültürüne katkı bağlamındaki potansiyelini gölgelemiş görünmektetir.

Meydan'ın kente kültürel ve sosyal katkı sağlaması için çaba gösteren isim 1957 yılından itibaren oniki yıl Viyana'nın belediye başkan yardımcllığını, 1970 yılından itibaren de belediye başkanlığını yürüten Felix Slavik olmuştur. Hedefi, araçlarla adeta bir 'çelik gölüne' benzeyen bu değerli alanın bir kentsel 'buluşma noktasına' dönüştürülmesidir. Meydanın farklı etkinliklerle tüm Viyanalılar için etkin bir 'buluşma noktasına' dönüşümünün en belirleyici olayı ise 1975 yılında Belediye Başkanı Leopold 
Gratz'ın, 1600 yılından itibaren kentin farklı bölgelerinde yapılan geleneksel Noel Pazarı (Christkindlemarkt) etkinliğini Belediye Meydanı'ına taşıma kararı olarak anılmaktadır (www.wien.gv.at).

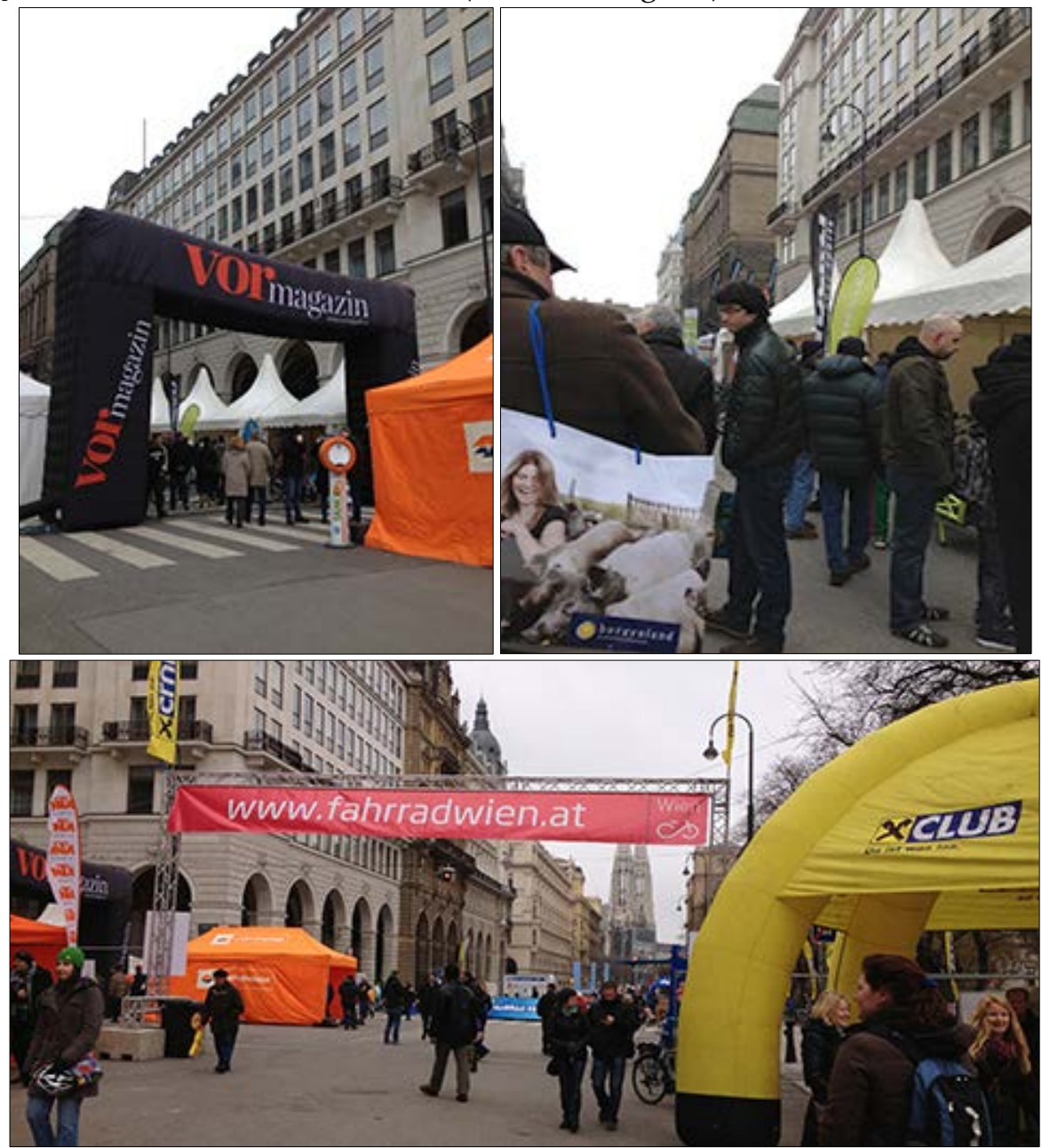

Resim 8 Viyana Belediye Meydanı'na çıkan sokaklar (Fotoğraf, yazarın arşivi)

Meydan'ın kentli ile bağ kurması yönündeki bir diğer önemli tarih, Meydan'da yaz aylarında gerçekleşecek bir açık hava film festivali etkinliği için karar alınan 1990 yılıdır. Festival yıllar içinde gelenekselleşmiş ve Viyanalılar'ın kentsel yaşamında önemli bir unsura dönüşmüştür. Denilebilir ki, 1990 tarihli bu festival oluşturma kararı, dolayımlı olarak, Belediye Meydanı'nda başka etkinliklere de olanak sunma ve buna göre mekansal tanzimler yapma anlayışını geliştirmiştir. Meydan'da düzenlenen 
etkinlikler zaman zaman sıradışı mekansal tanzimi gerektirmekte ve Meydan'a açlan sokaklarda (özellikle Felder Strasse ve Lichtenfelsgasse'de) belli bir canlılığı beraberinde getirmektedir (Resim 8).

Burada, görsellerle örneklenen bisiklet festivali etkinliği, hem cesur mekansal tezatı (ve "ödünç olma" durumunu) hem de Meydan'ın herkesçe erişilebilir olma niteliğini en sarih şekilde temsil edenlerden biridir. Bu etkinlikle birlikte, modern kentlerde giderek büyüyen çevre-dostu bir bilinçlenmenin önemli simgelerinden sayılabilecek bisiklet kültürü, Meydan'daki geçici mekansal biçimlenme ve pratikler aracılığıyla kentliye ulaşmaktadır. Meydanın ödünç ve akışkan kentsel mekan kimliği, durağan ve ağır neo-klasik mimari biçimlenmesinin önüne geçmekte ve kentlinin erişimine istisnasız açık olduğunun altı çizilmektedir. Bu durum, belediye, parlamento, üniversite ve tiyatro yapılarınca tariflenen otoriter mimari üslubun, toplumda karşılık bulan bir (sportif/çevreci) gerçekliğe dilsel bir çevirisi şeklinde tanımlanabilir. Gündelik dile çeviri olarak da kavramsallaşabilecek bu deneyim başka gerçeklikleri dolayısıyla farklı toplumsal ifadeleri içermektedir (Resim 9).
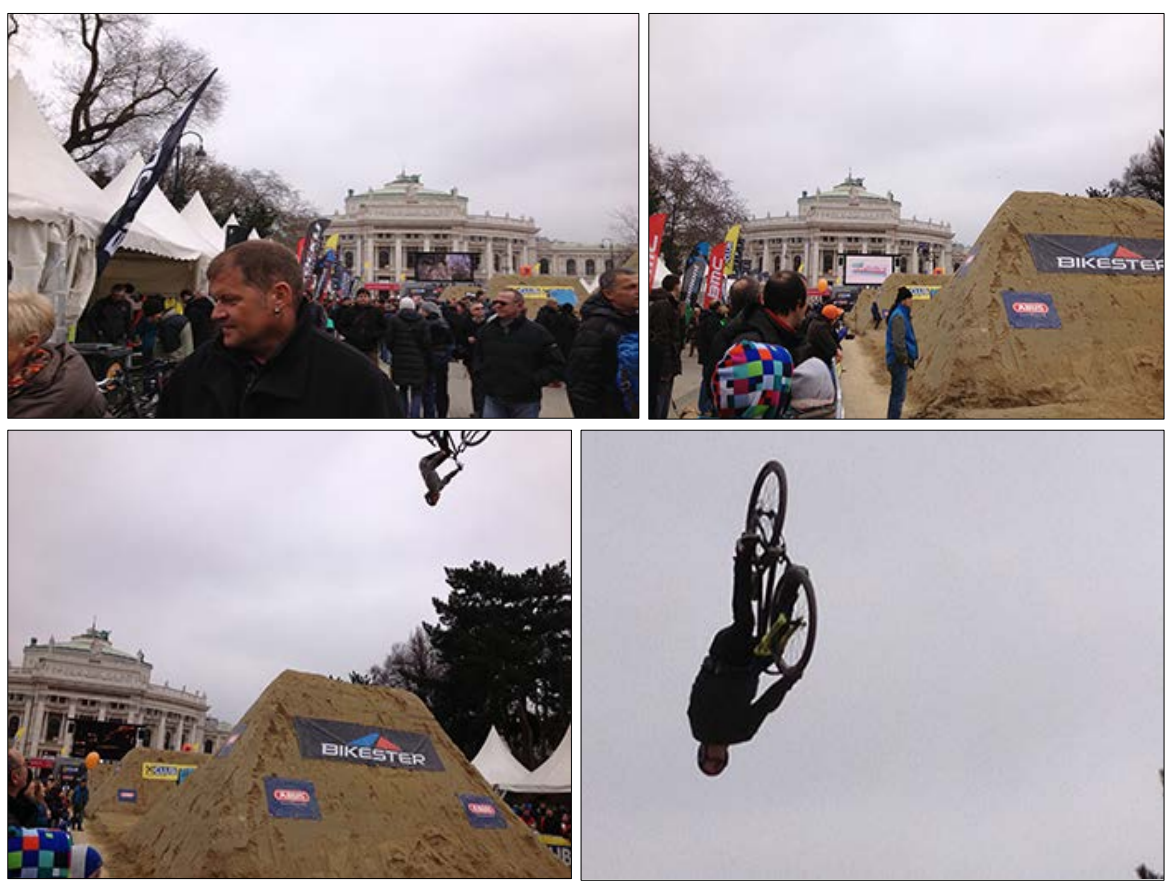

Resim 9. Meydanı tarifleyen yapılardan Tiyatro binası ve etkinlik (Foto: İnci Basa) 
Meydan, örneğin, her yıl düzenlenen 'Life Ball' etkinliğine ev sahipliği yapmakta ve AIDS hakkındaki toplumsal farkındalığa ve bilimsel çalışmaların finanse edilmesine katkı sağlamaktadır. Kalabalık gruplar, hayvan haklarının tanıtımına ve korunmalarının önemine (1846' dan beri faliyet gösteren Tierschutzverein öncülüğünde) yine Belediye Meydanı'nda ses verilmektedir. Kentli için sembolik önem taşıyan Viyana kent maratonunun (Wiener Stadtmarathon) ya çıkışı ya varışı Belediye Meydanı olmaktadır. Meydan, hem bireysel hem de toplumsal ölçekte, güncel ve çağdaş, gündelik ve sembolik anlamlar barındıran etkinliklere, işlevlere, hereketlere veya olaylara sadece dekor teşkil etmemekte, bu unsurlar burada üretilmektedir.

Modern kentsel yaşamın önemli bir bileşeni kentlinin serbest zaman aktiviteleri ve buna bağlı olarak kentin bu anlamda örgütlenebilme dağarcığıdır. Bir serbest zaman aktivitesi olarak her sosyal sınıftan ve yaştan kentlinin yoğun ilgisini çeken buz pateni etkinliği Belediye Meydanı'nın geniş çaplı bir fiziksel dönüşümüyle mümkün olmaktadır. Kentsel bir olaya dönüşen bu kış aktivitesine, iklimin ve kültürün getirdiği yatkınlıkla, bir buçuk aylık sürede 650.000 kişinin katılımı söz konusudur. İlk kez 1996 yılında 1800 m2'lik bir buz sahasıyla başlayan bu etkinlik yıllar içinde gelenekselleşmiş ve giderek daha büyük bir alan, buz yüzeyine dönüştürülmüştür; bugün, bu kış etkinliği, Belediye Binası önüne kurulan 8500 m2'lik bir buz sahasında ve park içinde oluşturulan buz kulvarlarında gerçekleştirilmektedir. Viyana Belediye Meydanı'nın fiziksel yapısı ve alg1sı bu mekansal pratiğin öncülüğünde yeniden tanımlanmaktadır.

Meydan ve kentli arasındaki bağ, festivaller, müzik dinletileri, film gösterimleri, yeni yılı karşılama, bölgesel tanıtım etkinlikleri, toplumsal günleri vurgulama etkinlikleri gibi bileşenlerden oluşan enerjiik bir programla güçlendirilmektedir (www.wiener-rathausplatz.at). ${ }^{6}$ Sürekli dönü-

\footnotetext{
${ }^{6}$ Meydan'ın 2017 programı genel hatlarıyla şu şekildedir: Ocak-Mart, buz pateni etkinliği (Eistraum/Buz Rüyası), Nisan, bölgesel tanıtım etkinliği (Steiermark eyaleti, Steiermarkdorf - yerel ürünler ve turizm potansiyeli üzerine), Mayıs, İşçi Bayramı kutlamaları, canlı müzik etkinlikleri, (modern ve folklorik konserler), Haziran, Life Ball (sivil toplum kuruluşu Aids Life (1992) öncülüğünde Avrupa'nın en kapsamlı AIDS'le mücadele etkinliği), TemmuzA ğustos, film festivali ve açık hava sineması (Filmfestival und Sommerkino) (23 m. x 13,25 m. ebadında dev ekran; giriş ücretsiz), önemli opera, bale, klasik müzik ve caz performanslarının yer aldığı film gösterimleri, uluslararası ve ulusal gastronomi etkinliği, her Pazar
} 
şüm halindeki toplumsal süreçlere ayak uyduran Viyana Belediye Meydanı, geçici kentsel ilhamlar aracılığıyla kalıcı kentsel bağlar kurmaktadır. Kozu, artık, mekanın, bir nesnel 'öz' olarak, modernitenin çoklu ve çeşitli yönelimlere sahip 'öznelerine' sunulamayacağını bilmektir. Modern kentsel kültür içinde, kamusal mekan yansız bir 'ortamdır', bir 'aracıdır' (Lefebvre, 1974/2014, s. 407-408); bir sonuç, içine hapsedildiği tarihsel bir kategori, soyut, siyasal, sosyal bir statü argümanı değildir.

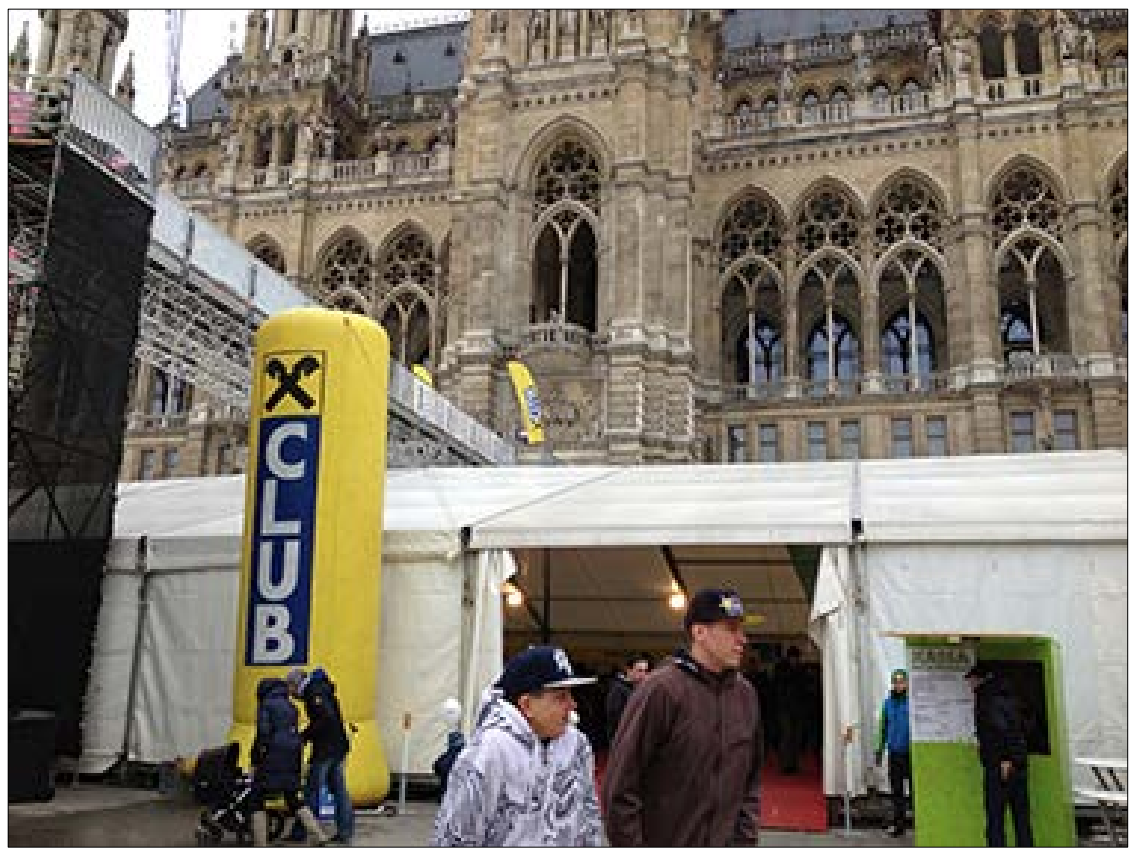

Resim 10 Belediye Binası ve geçici etkinlik mekanları (Fotoğraf, yazarın arşivi)

Lefebvre (1974/2014)'in 'mekanın tarihi' için öngördüğüne benzer biçimde; kamusal mekanın çözümlenmesi de, 'yapıların nesnelliği' ve 'toplumsal süreçler' arasında, 'değişmezlik' ve 'değişim' arasında, 'olay(sallik)' ve 'kurum(sallık)' arasında seçim yapmak zorunda değildir (s. 139). Dolayısıyla, Viyana Belediye Meydanı'nın çözümlemesi de bu unsurlar arasında seçim yapmak yerine bu ikililikler arasında kavramsal bir arayüz

günü canlı caz dinletisi (Jazz-Frühschoppen), Ekim, Viyana Güvenlik Şöleni (Wiener Sicherheitsfest) -50 yıldır düzenlenen etkinlikle kentlinin doğal afet, yangın, çevre, sağlık ve sosyal yardım alanlarında bilgilendirilmesi, Kasım-Aralı Noel Pazarı (Wiener Christkindlmarkt), 31 Aralık, yılbaşı etkinlikleri (Silvesterpfad Station) - canlı müzik / dans. Viyana Belediye Meydanı etkinlik programına için bkz. www.wiener-rathausplatz.at (12 Mart 2017 tarihinde erişilmiştir). 
oluşturmak için çeviri yapmaktadır. Meydan'ı çevreleyen yapıların oluşturduğu temsil, "bisikletin" neo-gotik kuleler hizasına yükselmesiyle semantik bir parçalanmaya uğramakta ve farklı bir dilsel ifadeye dönüşmektedir. Metaforik bir bakışla, mekansal pratik, varolan dilsel bütünlüğü parçalamakta ve değişen bir hiyerarşiyle yeniden oluşturmaktadır (Lefebvre, 1974/2014, s. 411). Anıtsal yapıların kalıcı nesnelliği ve geçici tentelerin eğretiliği birbirlerinin içinde çözülmekte ve bu 'çelişki çözüldügü̆' nisbette kamusal mekan 'düzenleyici' olmaktadır (s. 416) (Resim 10).

$\mathrm{Bu}$ anlayışta bir düzenleyicilik, tahakküm kurmanın kısıtlayıcılı̆̆ını altüst ederek 'tuhaf biçimde aşar' ve ödünç verilmeyi/alınmayı benimser. Ödünç mekan çoğunlukla uyumludur ve artı-değer paylaşımı eğilimindedir; zaman zamansa kışkırtıcı bir 'karşı-mekan' olarak içinden çıtığı mekanın 'parodisini' yapar (Lefebvre, 1974/2014, s. 382). Viyana Belediye Meydanı, mekanı bu bağlamda kavramamıza vesile olmaktadır. 


\section{Extended Abstract}

\section{Borrowed Urban Spaces: Analysis of a Square, Vienna City Hall Square (Wiener Rathausplatz)}

İnci Basa

Middle East Technical University

This essay is an outcome of an initial concentration in urban public space, which led to a specific interest in the investigation of the practice of "borrowed spaces" as remarkable modes of spatial production in cities. Considering the concept of "borrowed space" as a mechanism that transforms the urban open spaces into a 'locus of possibilities', the present study aims to analyse the Vienna City Hall Square (Wiener Rathausplatz) through its identification as a borrowed space that successively introduces different practices via a spatial adaptability to cultural, festive, sportive and social occasions and events. The original scholarly contribution here can be portrayed as this mechanism's representation as a translation between 'social processes' and 'spatial form', (the dual components which have been widely recognized in the understanding of complexity of the urban structure) and its utilization as a theoretical framework within the analysis of the Square in question.

The exceptional architectural/urban texture of the capital city of Vienna is characterized by the harmonious connection of an early Modernist language (presented principally by Otto Wagner and Adolf Loos) to the city's historicist / revivalist buildings. In this respect, it appears normal that powerful and tangible architectural expressions may dominantly outline the perception of the city image, and may blockade the perceptions of the Viennese urban everyday life from other perspectives and through dynamic spatial/functional superimpositions. On the other hand, considering a perception through possibilities and diversity in urban life seems 
indispensable for developing both a contemporary rhetoric of urban public space and an awareness of altering patterns in ways it is used, as well as defensing its significance in societal terms in enhancing the quality of urban life.

The concept of publicness frequently reflects its semantic duality (that of belonging to the society yet implying a relationality with state) upon the space, especially upon the ones organized by the state and governments. However, in the cities with an ever-growing density, public spaces actually possess a certain potential of becoming the grounds of counterresistance against the spatial dissociation. As a matter of fact, in one's mind, the image of a good city and lively urban public spaces are mostly intertwined. Vienna, as one of the European cities affirming this argument, is best known for its numerous public spaces, squares, parks, and moreover for its urban(ite) culture that integrates these spaces into life effectively. Within this understanding, the Vienna City Hall Square participates to the urbanite's everyday practices as a dynamic urban public space via the social, political, cultural, artistic, sportive facilities, thus, transcends the institutional and tectonic monumentality of the surrounding neo-classical buildings of City Hall, Parliament, University and Theatre by a new urban / spatial meaning. This meaning produced by the Vienna City Hall Square as a 'borrowed space' stands for an accessibility for all social strata of the society and a strong urban bond with the citizens.

As mentioned above, the Vienna City Hall Square occupies a central location in the city and offers spatial possibilities to well-attended events and activities. Nevertheless, regarding these qualities, one should not suggest that the Square, or any other such spaces in cities, automatically merges into the spatial practices of the urbanites and the urban everyday life. Evidently, many spaces with similar characteristics cannot receive public attention and cannot find place within the spatial practices of the urbanites. For the transformation of the qualities such as centrality, openness, accessibility etc. into an urban value there exists the necessity of sustainable socio-political decree and of course a public demand. When one scrutinizes how the Square attained such significant status within Viennese's spatial practice, she/he encounters the fact that this space is being borrowed by various subjects, groups and institutions for conducting a variety of activities throughout the whole year. The local government of Vienna adopts this mechanism as a way of contributing to the general texture of the modern urban life and enriching the routines of the urbanite's 
everyday life. From classical or jazz concerts to film festivals, from marathon start-up to bicycle days, a plenty of leisure time activities as well as social and cultural facilities produce their own temporary spatiality in the Vienna City Hall Square. In a temporal sequence and with a specific spatial organization regarding the activity, either the temporary tents, shortterm stages or the ice rink faces the neo-gothic façade of the architect Friedrich von Schmidt's City Hall building (Wiener Rathaus) constructed in the late $19^{\text {th }}$ century in the Innere Stadt district.

Considering the pluralities and multiplicities of this particular urban space, the Viennese Square, the space becomes 'intermediary'; it becomes an active 'milieu'; and, as Lefebvre (1974/2014, p. 408) indicates, it becomes both 'instrument' and 'goal', 'means' and 'end'. Urban spaces, yet the ones which obtain their identity through the opportunities they offer instead of a place-fixed program, feed and/or (re)produce urban culture in a multidimensional sense involving several aspects. Within such a condition, the authoritative, permanent and monumental architectural essence there, is urged to yield up these attributes and required to redefine its essence anew within the indefinite bounds of the everydayness of urban culture that can by no means be excluded. In the Vienna case, architectural monumentality and everyday variables overlap to a certain extent. Regarding this overlapping, it can be argued that the power relationality between them has been transformed in the favour of the everyday life. In the examined Vienna City Hall Square, one may well conclude that a skill of attuning occurs among different even conflicting elements as an urban virtue.

\section{Kaynakça/References}

Basa, İ. (2016a). Söylemsel zapturapt: kamusal mekan eli (/dili) ile kentsel kültürü ehlileştirmek. Arredamento Mimarlik, 301, s. 96-101.

Basa, İ. (2016b). Sosyopolitik zıtlaşmaya inat açı aklın mekanları: zor bir önerme olarak Ankara Atatürk Kültür Merkezi. Mimarlık, 391, s. 56-60.

Harvey, D. (2009). Sosyal adalet ve şehir. (M. Moralı, Çev.) İstanbul: Metis. (Orjijinal eserin yayın tarihi 1973).

Harvey, D. (2013). Asi şehirler. (A. D. Temiz, Çev.) İstanbul: Metis. (Orjijinal eserin yayın tarihi 2012).

Haeupl, M. (2009). Politik für die Menschen: Perspektiven für sozialdemokratische Politik im 21. Jahrhundert. (İnsanlar için siyaset: 21. yüzyılda sosyal demokrat siyaset perspektifleri). Bergamo: Echomedia Verlag.

Hofer, G. (2008). Die Festivalisierung der Stadt: Am Beispiel des Wiener Rathausplatzes (Viyana Belediye Meydanı örneğinde şehrin festivalleştirilmesi). Diplomarbeit Universitat Wien, Viyana. 
Igler, N. (2013). Turbo für Einzelhandel und Tourismus (Satış ve turizm için turbo), ORF (Österreichicher Rundfunk / Avusturya'nın resmi radyo ve televizyon kurumu) http://orf.at/stories/2207162/2207008/ adresinden 21 Mart 2017 tarihinde erişildi.

Lefebvre, H. (2014). Mekanın üretimi. (I. Ergüden, Çev.) İstanbul: Sel Yayıncılık. (Orjijinal eserin yayın tarihi 1974).

Migration und Integration: Zahlen, Daten, Indikatoren (Göç ve entegrasyon: sayılar, tarihler, göstergeler) (2016). BMEIA Bundesministerium für Europa, Integration und Ausseres (Federal Dışişleri Bakanlığ1 Yayını) Yayına

http://www.wien.gv.at/menschen/integration/grundlagen/daten.html adresinden 13 Mart 2017 tarihinde erişildi.

Sisa, J. (2002). Neo-Gothic Architecture and restoration of historic buildings in Central Europe: Friedrich Schmidt and his school. Journal of the Society of Architectural Historians, 61(2), 170-187.

Smith, A. (2014). 'Borrowing' public space to stage major events: the Greenwich Park controversy. Urban Studies, (51), 247-263.

www.wien.gv.at/kultur/chronik/rathausplatz.html adresinden 14 Mart 2017 tarihinde erişildi.

www.wiener-rathausplatz.at adresinden12 Mart 2017 tarihinde erişildi.

Doç. Dr. İnci Basa Orta Doğu Teknik Üniversitesi, Mimarlık Bölümü'nde öğretim üyesi olarak görev yapmaktadır. Lisans, yüksek lisans ve doktora derecelerini ODTÜ Mimarlık Bölümü'nden alan Basa, HTA-Bern, İsviçre'de 'post-doc' çalışmaları yapmıştır. Araştırma konuları arasında kentsel kamusal mekan, mimarlık söylemi, söylem çözümlemesi ve mimarlık-dil ilişkisi bulunmaktadır. Makaleleri Journal of Urban History, International Journal of Environmental Studies, International Journal of Technology and Design Education, Design Studies, Turkish Historical Review, International Journal of Art and Design Education gibi dergilerde yayınlanmıştır.

Assoc. Prof. Dr. İnci Basa currently teaches in the Department of Architecture at Middle East Technical University. She received the B. Arch, M. Arch and Ph.D. degrees from METU. She made post-doctoral studies in HTA-Bern, Switzerland. Her research interests include urban public space, architectural discourse, discourse analysis and architecture-language relationship. Her articles were published in various journals such as Journal of Urban History, International Journal of Environmental Studies, International Journal of Technology and Design Education, Design Studies, Turkish Historical Review, International Journal of Art and Design Education.

E-mail: basa@metu.edu.tr

\section{Kaynakça Bilgisi / Citation Information}

Basa, İ (2018). Ödünç kentsel mekanlar: bir meydan çözümlemesi, Viyana Belediye Meydanı (Wiener Rathausplatz). IDEALKENT - Kent Araştırmaları Dergisi, 23, 236-257. 